\title{
Socialização de gênero na educação infantil: continuidades e rupturas vivenciadas pelas crianças na família, na igreja e na escola
}

Resumo $\mathrm{O}$ artigo analisa a socialização de gênero vivenciada por crianças de cinco anos no interior de uma instituição de Educação Infantil. A partir de um referencial teórico-metodológico que articula os estudos de gênero e os estudos da infância, discute-se as tensões e ambiguidades presentes nos diferentes processos de socialização de gênero vivenciados por meninos e meninas no interior de uma instituição de Educação Infantil situada em Belo Horizonte, Brasil. Os resultados derivam de uma etnografia que teve como principais instrumentos de produção de dados: a observação participante com registros fotográficos e notas em caderno de campo, entrevistas com crianças e adultos e desenhos conjugados com as falas de meninos e meninas. Ao longo do artigo, são descritas e analisadas as ambiguidades e as controvérsias que regem o complexo e multifacetado processo de socialização de gênero na Educação Infantil. Nesse sentido, para além dos processos de socialização de gênero vivenciados pelas crianças na interação com seus pares e com os/as docentes da instituição de Educação Infantil, verificou-se também o atravessamento de outros processos de socialização procedentes de diferentes instituições (como a família e as instituições religiosas).

PALAVRAS-CHAVE: Educação infantil; Socialização de gênero; Crianças. 


\section{Gender socialization in the early childhood education: continuities and ruptures lived by children in the family, in the church and school}

Abstract The article analyzes the gender socialization experienced by five year old children within a school of early childhood education. Based on a theoretical framework that articulates gender studies and childhood studies we discuss the tensions and ambiguities in the different gender socialization processes experienced by boys and girls within a school of early childhood education located in Belo Horizonte, Brazil. The results were derived from data produced by an ethnographic study, which applied participant observation with the support of photographic records and fieldnotes. We carried out interviews with some of the children and adults from the school and family. Particularly, with the children, we guided an interview combined with drawing, which were also analyzed. We described and analyzed the ambiguities and controversies that govern this complex and multifaceted process of gender socialization in early childhood education are. In addition to the processes of gender socialization experienced by children in the interaction with their peers and the teachers of their school, we observed other socialization processes originated/rooted (in) from different institutions (such as the family and religious institutions) crossing throughout the gender socialization processes in the school.

KEYWORDS: Early childhood education; Gender socialization; Children's.

\section{Introdução}

Procurando bem; Todo mundo tem pereba; Marca de bexiga ou vacina. E tem piriri, tem lombriga, tem ameba; só a bailarina que não tem. E não tem coceira verruga nem frieira; nem falta de maneira ela não tem

(Chico Buarque, 1983).

Este texto objetiva discutir a conjugação de diferentes processos de socialização de gênero vivenciados por crianças de cinco anos de idade em uma instituição pública de Educação Infantil. Pretende-se, portanto, nas breves linhas deste artigo descrever como se articulam, deslocam e, por vezes, concorrem diferentes processos de socialização de gênero vividos por adultos e crianças no âmbito das experiências de cuidado e educação em um contexto público de Educação Infantil.

A beleza e a potência dos versos de Chico Buarque contidos na epígrafe acima nos convidam a refletir sobre o conteúdo que será desenvolvido ao longo do artigo. Nessa música, cuja letra é de sua autoria e a melodia feita em parceria com Edu Lobo - oitava faixa do álbum "O Grande Circo Místico", de 1983, o autor, de modo delicado, provoca-nos a uma complexa, densa e intensa ponderação sobre a infância.

Por possuir uma melodia alegre e simples seguida de uma estrutura poética repleta de jogos de rimas, aliterações e repetições ricas em imagens comuns ao univer- 
so infantil, tais como: pereba, vacina, ameba, falta de maneira, irmão zarolho, piolho, bigode de groselha, primeiro namorado e mesmo a falta de pelos; a canção contribui facilmente para a identificação de meninos e meninas, além de suscitar memórias de infância em nós, adultos.

A bailarina, personagem principal do enredo, com toda sua graciosidade, é descrita quase que como uma entidade mítica, divina, a quem devemos contemplar, não possuindo defeito algum. Ao longo da música, somos lembrados repetidas vezes dos defeitos, das doenças, dos problemas, da sujeira, dos medos que todos(as) temos, e apenas ela, a bailarina, não possui.

Chico Buarque, impulsionado por sua capacidade criativa, constrói essa imagem em torno de uma personagem muito presente em nosso imaginário coletivo. A bailarina, expressão da beleza e da graciosidade feminina (adjetivos comumente associados a uma representação hegemônica de menina/mulher), para atingir a perfeição estética, necessita percorrer um extenso e duro processo de aprendizagem da dança clássica. Desse modo, a música amplia nossa compreensão de como a infância é atravessada por processos de socialização, dentre os quais destacamos aqueles que visam a fabricação social de meninos e meninas, processos estes influenciados por distintas representações de gênero.

Por representações simbólicas de gênero, compreende-se o conjunto de formas culturalmente organizadas que possibilitam aos sujeitos aludir, classificar, mostrar ou nomear a si mesmos, as pessoas e as coisas com base nas diferenciações historicamente construídas entre a masculinidade e a feminilidade. As representações simbólicas provenientes das relações de gênero não são meros reflexos da realidade, mas constituintes do "real". Desse modo, não cabe questionar "se uma representação 'corresponde' ou não ao 'real', mas, ao invés disso, como as representações produzem sentidos, quais seus efeitos sobre os sujeitos, como elas constroem o 'real”' (LOURO, 1997, p. 98-99).

Analogicamente, podemos perceber que a fabricação - seja da bailarina, seja do herói valente e destemido - como sujeito gendrado é fruto de intenso processo de socialização no qual uma sociedade busca transferir suas expectativas às crianças, num exercício de produção de subjetividades opostas: de um lado as meninas são concebidas como seres dóceis e delicados, enquanto os meninos são considerados sujeitos rudes e aguerridos (BELOTTI, 1975 [1973]). Em ambos os casos, tanto na socialização das meninas quanto dos meninos, a fabricação de sujeitos gendrados, pressupõe a articulação e combinação (ou não) de diferentes processos de socializadores.

Assim, objetivando analisar os diferentes processos que se articulam na fabricação sociocultural de meninos e meninas e compreendendo o gênero como resultante de um conjunto de códigos culturais produzidos sobre e a partir dos modos como os corpos são socialmente significados ao passo em que são concomitantemente construídos (WEST e ZIMMERMAN, 1987), o artigo busca responder a seguinte questão: como são organizados os processos de socialização de gênero vivenciados pelas crianças nas instituições de Educação Infantil? 
Com o intuito de responder esta e outras questões, buscou-se inspiração em um quadro teórico-metodológico produzido na interseção dos estudos de gênero (BELOTTI, 1975 [1973]; WEST e ZIMMERMAN, 1987; LOURO, 1997; CONNELL e PEARSE, 2015, dentre outras(os) com os estudos da infância (PROUT e JAMES, 1997; MOLLO-BOUVIER, 2005; COHN, 2005; PIRES, 2007, dentre outras(os) - áreas que visam construir, cada qual a seu modo, uma interpretação descolonizada sobre a realidade social, isto é, uma explicação para os fenômenos sociológicos que conteste respectivamente visões androcêntricas e adultocêntricas fortemente presentes ainda hoje no pensamento social contemporâneo.

O trabalho de campo, desenvolvido de fevereiro a dezembro de 2015, consistiu em uma etnografia realizada na interlocução com uma turma de crianças de cinco anos de idade (sete meninas e dezoito meninos) e a professora ${ }^{1} \mathrm{em}$ uma Unidade Municipal de Educação Infantil (UMEI), situada em Belo Horizonte, Minas Gerais. As descrições etnográficas desenvolvidas com essas crianças permitiram compreender os significados que elas "constroem nas suas ações situadas de todos os dias, isto é, situadas no contexto cultural e nos estados mutuamente intencionais de interação dos participantes"(GRAUE e WALSH, 2003, p. 59).

Como forma de aceder ao ponto de vista das crianças, fez-se necessário articular a observação participante e os registros em caderno de campo a outras técnicas de produção de dados (COHN, 2005). Nesse sentido, também foram produzidos pelas crianças desenhos que, ao serem conjugados com suas falas, permitiram interpretar as diferentes formas de masculinidades e feminilidades que circulam entre meninos e meninas. Além disso, foram realizadas entrevistas com as crianças como forma de compreender as especificidades das relações de gênero por elas vivenciadas. A articulação entre tais instrumentos de pesquisa foi realizada com o objetivo de viabilizar a construção de uma descrição densa (GEERTZ, 1989 [1973]) acerca dos processos de socialização de gênero vivenciados pelas crianças dentro da instituição de Educação Infantil.

Cumpre esclarecer que os desenhos produzidos por meninos e meninas quando conjugados com suas falas se conformam como artefatos que possibilitam ao pesquisador uma maior compressão da produção simbólica infantil, uma vez que se tornam elementos privilegiados de análise em um estudo etnográfico com crianças ${ }^{2}$ (PIRES, 2007; SARMENTO, 2011). Nesse sentido, os desenhos infantis são especialmente apropriados para aceder a formas de expressão próprias das crianças possibilitando, dessa maneira, interpretá-los "como actos de criação cultural que revelam, mais que processos biopsicológicos de desenvolvimento, formas específicas de aç̧ão social das crianças" (SARMENTO, 2011, p. 40).

$\mathrm{O}$ artigo está dividido em quatro seções. Na primeira seção, são apresentados os aportes teóricos que serviram como lentes interpretativas capazes de ampliar nossa compreensão acerca das relações de gênero na Educação Infantil. $\mathrm{Na}$ segunda seção, são discutidas as tensões e ambiguidades dos processos de socialização de gênero no interior da instituição de cuidados e educação. $\mathrm{Na}$ seção seguinte, são apresentados e discutidos as continuidades e rupturas dos processos de socialização de gênero 
vivenciados na família e nas instituições religiosas com aqueles vividos na instituição de Educação Infantil. Por ultimo, apresentam-se algumas considerações finais.

\title{
Infância e gênero
}

Os estudos da infância, subdisciplina emergente no quadro de referência das ciências sociais, têm reivindicado um novo paradigma para a investigação científica das formas de vida das crianças, desconstruindo noções anteriormente presentes no pensamento social que concebiam meninos e meninas como tábulas rasas, desconsiderando suas ações e experiências sociais no presente e, consecutivamente, viam a infância como tempo de preparação para a vida adulta (JAMES e PROUT, 1997).

Esse novo paradigma de investigação da infância sustenta uma severa crítica às formas como ocorre, na atualidade, a socialização de meninos e meninas. A socióloga francesa Suzanne Mollo-Bouvier (2005), por exemplo, considera que as transformações do ambiente familiar têm efeitos diretos sobre os processos de socialização das crianças. Para ela, a socialização não deve ser tomada na acepção formulada por Durkheim (2011 [1922]) cuja compreensão consistia na integração dos indivíduos ao corpo social. Pelo contrário, a autora defende que a socialização deve ser compreendida "numa perspectiva interacionista que salienta a dinâmica das interações na aquisição de know-hows e insiste no vínculo entre conhecimento de si e conhecimento do outro, construção de si e construção do outro" (MOLLO-BOUVIER, 2005, p.392).

Nessa perspectiva, as crianças são concebidas como atores sociais cujas experiências são construídas frente a um quadro de referências cada vez mais diversificado, participando, ao mesmo tempo, de distintos processos socializadores oriundos de diferentes instituições (família, escola, instituições religiosas) ao passo em que são também por elas afetadas. Ao lançar novas luzes sobre os modos ativos, genuínos e interativos de participação de meninos e meninas em sua própria socialização (por meio dos diferentes processos nos quais eles(as) se inserem), evidencia-se o dinamismo e a pluralidade constitutiva desse processo. Nesse sentido, considera-se que, na atualidade,

\begin{abstract}
A socialização compõe-se de dessocializações e ressocializações sucessivas. Ela é a conquista nunca alcançada de um equilíbrio cuja precariedade garante o dinamismo. Em contrapartida, essa concepção interacionista da noção de socialização implica que se leve em conta a criança como sujeito social, que participa de sua própria socialização, assim como da reprodução e da transformação da sociedade (MOLLO-BOUVIER, 2005, p. 393).
\end{abstract}

Estudiosos(as) das relações de gênero (LOURO, 1997; CONNELL e PEARSE, 2015, dentre outras(os) também corroboram essa crítica aos processos de socialização. Desse ponto de vista, percebe-se que os processos que se conjugam para a fabricação de sujeitos gendrados (socialização de gênero) não ocorrem somente pela imposição do corpo social sobre os sujeitos, mas também se dão por meio de processos interativos nos quais se evidencia, cada vez mais, a capacidade de ação de adultos e crianças. Cabe destacar que tais processos não ocorrem de modo linear, visto que são marcados por descontinuidades e rupturas. 
Na vida cotidiana, o gênero é apreendido e simultaneamente vivenciado pelos indivíduos. Na maioria dos casos, reconhecemos a nós mesmos e aos outros como homens e mulheres ${ }^{3}$; meninos e meninas e, mais: realizamos nossos afazeres, nossas relações sociais e nossas atribuições com vistas a essa distinção. Compreende-se, desse modo, que o gênero se constitui no terreno das relações sociais nas quais os indivíduos e grupos atuam; trata-se, pois de um construto individual metódico, recorrente e situado nas interações interpessoais (WEST e ZIMMERMAN, 1987), nas quais os indivíduos constroem o gênero ao passo em que são por ele produzidos.

Connell e Pearse (2015, p. 38) sugerem que ser homem e ser mulher não são estados determinados previamente. Pelo contrário, trata-se de processos que resultam de uma construção ativa. As autoras vão buscar inspiração em Simone de Beauvoir (1980 [1949]) para evidenciar que a masculinidade e a feminilidade resultam de um extenso processo de "fabricação" sociocultural e histórico, ou seja, os modos pelos quais nos tornamos pessoas generificadas (sujeitos de gênero) derivam de processos sociais distintos, repletos de tensões e ambiguidades.

Nessa perspectiva, a masculinidade e a feminilidade são consideradas construções sociais resultantes de um amplo percurso de "fabricação" histórico e cultural, já que, desde o nascimento, vivenciamos diferentes processos de socialização, muitas vezes ambíguos e controversos em que diferentes códigos e estruturas sociais (generificadas) nos são impostos. Ou seja, os modos pelos quais nos tornamos sujeitos de gênero procedem da conjugação de diferentes processos de socialização, repletos de tensões e ambiguidades, nos quais, inclusive, os sujeitos fabricam a si próprios.

Enquanto dimensão da identidade pessoal, o gênero se constitui no terreno das interações, nas quais os indivíduos e grupos ativamente se engajam. Isso permite considerar o gênero como uma dimensão estruturante das relações sociais (SILVA e LUZ, 2010). Nas palavras de Connell e Pearse (2015, p. 47), "a manutenção de padrões amplamente difundidos entre relações sociais é o que a teoria social chama de 'estrutura'. Nesse sentido, o gênero deve ser entendido como uma estrutura social”. Contudo, não se trata de uma estrutura social qualquer, mas de um tipo muito particular, pois envolve uma relação específica com os corpos femininos e masculinos. O gênero, portanto, se conforma como uma "estrutura de relações sociais que se centra sobre a arena reprodutiva e o conjunto de práticas que trazem as distinções reprodutivas sobre os corpos para o seio dos processos sociais" (CONNELL e PEARSE, 2015, p. 48).

Analisado nessa chave, o gênero passa a ser concebido como uma forma peculiar de corporificação social ${ }^{4}$, isto é, um processo de estruturação que conecta a agência humana às estruturas sociais, situando ambos - agência e estrutura - num quadro tanto sincrônico quanto diacrônico (CONNELL e PEARSE, 2015). Nesse sentido, as aprendizagens de gênero se dão em uma arena reprodutiva, isto é, num campo de ação corporal ligado aos processos reprodutivos, no qual meninos(as) necessitam ser socializadas(os) para garantir a reprodução social.

O conjunto das capacidades corporais somado às práticas pelas quais elas são realizadas constitui uma arena, "um campo corporal em que algo social acontece." 
Entre essas ocorrências estão as categorias culturais "homem" e "mulher" - e a partir delas, todas oposições binárias que uma sociedade define, tais como: meninos e meninas, agressividade e docilidade; masculinidade e feminilidade, brutalidade e sensualidade, dentre outras, e "isso pode ser chamado de 'arena reprodutiva' na vida social" (CONNELL e PEARSE, 2015, p. 113). Assim, a fabricação de sujeitos de gênero (que como veremos, dá-se por meio da articulação de diferentes processos de socialização), por basear-se em binarismos constitutivos da arena reprodutiva, pressupõe a docilização das meninas e o desenvolvimento da valentia dos meninos (BELOTTI, 1975 [1973]).

Essas afirmações trazem implicações importantes para pensarmos os processos de socialização de gênero vivenciados na infância na medida em que possibilitam a percepção dos "diferentes poderes utilizados nas negociações cotidianas, e compreender os processos institucionais e socializantes que a criança vivencia" em seu ambiente social (FINCO, 2013, p. 174).

\section{Socialização de gênero na educação infantil}

No âmbito da empiria, buscou-se compreender como ocorre a socialização de gênero no interior da instituição de Educação Infantil. A partir de um quadro teórico-metodológico capaz de amplificar as vozes das crianças e que, igualmente, possibilitou apreender a densidade e a complexidade de suas experiências sociais, evidenciou-se a presença de atitudes, visões e algumas representações de gênero no cotidiano institucional de meninos e meninas; homens e mulheres.

Durante a observação participante, foram registradas inúmeras situações em que os adultos objetivavam reforçar junto às crianças comportamentos tipicamente ajustáveis às condutas associadas a visões hegemônicas de gênero (CONNELL, 1995). Nesse sentido, foi possível perceber que, em diversas situações cotidianas, a docente, assim como outros(as) profissionais da instituição, realizava certo controle e vigilância sobre o comportamento de meninos e meninas, como pode ser observado no episódio a seguir:

Em certa altura da correria dos meninos, Saulo - um dos garotos que estava sendo perseguido - é empurrado e acaba caindo. Sua queda ocorreu bem próxima à professora Wânia, que se vira imediatamente para ele. Saulo, logo que caiu, olhou em direção à docente com ares de quem temia ser reprimido ao mesmo tempo em que queria esboçar seu incômodo em ter caído. Esta, por sua vez, se antecipando a qualquer comportamento do menino fala:

Wânia: - "Ah não! Não chora não! Menino não chora!" - O menino se levanta sem dizer nada e continua a correr com os amigos (notas do caderno de campo 04 de março de 2015).

A professora, sem se dar conta, não permite demonstração de qualquer natureza por parte do menino, antes mesmo de verificar se ele não havia se machucado. A forma incisiva como ela o reprime faz com que a criança contenha qualquer manifestação de dor ou desconforto, incluindo o choro. Essa noção, muito presente no senso comum, que associa um comportamento aguerrido aos meninos e refuta as dife- 
rentes formas de sensibilidade (inclusive o choro), convive com outra ideia fortemente difundida no interior da instituição e que concebe as meninas como sujeitos dóceis, delicados e mais sensíveis em relação aos garotos. Assim, se por um lado atitudes de sensibilidade como o choro não são permitidas a um menino, agressividade é um comportamento a ser "contido" nas meninas (BELOTTI, 1975 [1973]).

Esse é o caso apontado por Cristiano que, ao apresentar o desenho que produziu quando lhe foi pedido para registrar o brinquedo de que mais gostava, relata uma interdição vivida por uma amiga de sala (e feita pela professora). Segundo ele, ao ser negado o direito de poder brincar com os meninos, sua colega (Mirela), descontente com a proibição, saiu "emburrada":

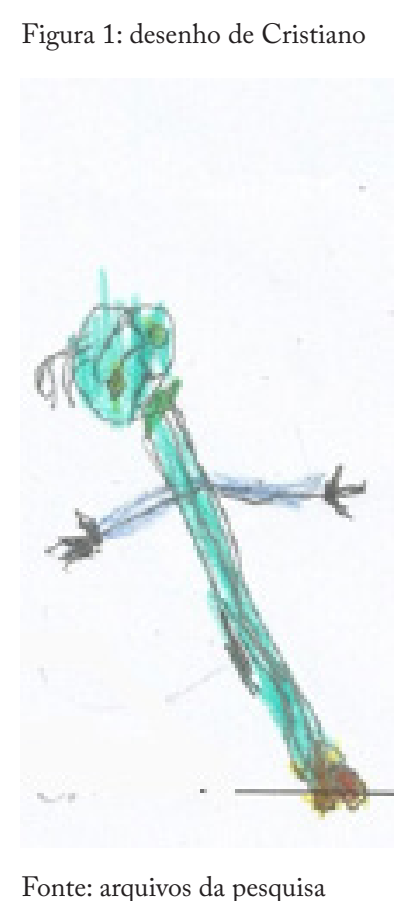

Pesquisador: - "Tem coisas que os meninos fazem que as meninas não possam fazer"?

Cristiano: - "Tem. Tipo... lutinha. Elas nunca brincam. Outro dia, a Mirela até quis brincar, mas a professora Wânia não deixou. Falou que ela era delicada pra essa brincadeira".

Pesquisador: - "E a Mirela, como ficou"?

Cristiano: - "Sei lá. Ela saiu pra lá emburrada. Depois foi brincar de pecinhas" (Cristiano desenha "o brinquedo que eu mais gosto" -27 de agosto de 2015). 
No âmbito das entrevistas, também emergiram elementos que permitiram inferir que as crianças percebiam que os adultos repreendiam comportamentos considerados por eles impróprios para meninos e meninas. Nas falas das crianças, fica evidente que essa interdição dos adultos era atravessada por representações de gênero:

"A professora mesmo fala que não é para as meninas brincarem de super-herói com a gente por que os meninos são brutos” (Carlos, 21 de setembro de 2015).

"Meninas não fazem bagunça. A professora Wânia fala sempre isso. Senão fica parecendo com os meninos. Eles brincam de super-herói e correm, gritam, fazem uma bagunça só e caem e acabam machucando" (Isabela, 15 de setembro de 2015).

As práticas cotidianas vivenciadas por adultos e crianças nas instituições de Educação Infantil demostram que os(as) professores(as) proporcionam distintas experiências aos meninos e às meninas fundamentados(as) "nos modelos de masculinidade e feminilidade padronizados em função de uma questionável naturalização do que é "mais adequado" para cada sexo e repreendendo o que consideram inadequado" (SILVA e LUZ, 2010, p. 25).

Se em algumas situações, a professora, sem se dar conta, contribui para a legitimação de estereótipos de gênero, em outras, esta profissional se esforça para combater preconceitos e atitudes desrespeitosas no que diz respeito a igualdade de oportunidades para meninos e meninas. Desse modo, considera-se pertinenente salientar que o mesmo ambiente que legitima papéis culturalmente padronizados permite, também, o exercício da crítica (SILVA e LUZ, 2010). Isso pode ser observado no episódio a seguir:

Ao se aproximar de $10 \mathrm{~h} 00 \mathrm{~min}$ a professora Wânia pede que as crianças arrumem a sala para que ela as leve para brincar no pátio. Como de costume, as meninas iniciam a arrumação, assessoradas por alguns poucos meninos. Como essa postura da maioria dos garotos (de não contribuir com a arrumação) é recorrente, a professora Wânia intervém:

Wânia: - "Ah não. Meninos, vocês não vão ajudar? Então tá. As meninas, só as meninas, podem sentar aqui fora. Os meninos, enquanto não guardarem tudo e arrumarem a sala, não irão brincar lá fora". - os meninos então, rapidamente, se engajam na arrumação e Wânia, vai liberando-os pouco a pouco para sentarem-se do lado de fora da sala de referência com as meninas. Assim que terminam, ela leva todos(as) para o pátio (notas do caderno de campo - 27 de maio de 2015).

Esse episódio demonstra que, se por um lado, as ações e práticas da professora, muitas vezes, reafirmam o que se espera socialmente de meninos e meninas; homens e mulheres, por outro, percebe-se que, em muitas situações, a docente também busca diminuir as desigualdades de gênero presentes na educação das crianças. 


\section{Continuidade e rupturas na socialização de gênero}

O contato estabelecido com crianças e adultos na instituição de Educação Infantil permitiu perceber a presença de diferentes processos de socialização de gênero advindos de outras instituições sociais e que ora se cruzam, ora se contrapõem àquele realizado pela instituição de cuidados e educação.

Conforme sugerem Connell e Pearse (2015), sendo o gênero uma estrutura da sociedade cuja organização pressupõe a corporificação social, isto é, um processo de conexão da agência humana às dimensões estruturantes, as aprendizagens de gênero se dão em uma arena reprodutiva - campo de ação corporal no qual a reprodução societal é garantida pelo processo de socialização das novas gerações de meninos e de meninas.

Essa abordagem teórica contraria a perspectiva analítica que considera a socialização dos papéis de gênero como um processo unilateral, no qual a sociedade incute nas crianças as identidades masculinas e femininas (CONNELL e PEARSE, 2015) e desse modo, permite compreendê-la como um conjunto de processos ora concorrentes, ora articulados, que obrigam os sujeitos (no caso as crianças) a produzir suas próprias experiências - combinando diferentes processos socializadores.

Durante muito tempo, as teorias sobre a socialização de gênero, afirmaram que as pessoas aprendiam os papeis sociais destinados ao masculino e ao feminino pela via de uma socialização vertical, isto é, aquela realizada de modo impositivo por diversas instituições como a família, a escola, os grupos de convivência e mais recentemente a mídia. Entretanto, autores(as) do campo da sociologia têm discutido a insuficiência dessas teorias da socialização afirmando que não se trata de uma imposição de papéis sociais às pessoas, mas sim um processo de apropriação que pressupõe simultaneamente a construção de um conhecimento sobre si e sobre os outros (MOLLO-BOUVIER, 2005). Tais correntes teóricas consideram a participação ativa dos sujeitos nos processos de socialização dos quais eles participam (principalmente àqueles relativos à socialização de gênero).

Esses estudos também têm demonstrado que, na atualidade, os atores se deparam com um conjunto cada vez mais diversificado e heterogêneo de instituições que pressupõem e, simultaneamente, estabelecem diversas possibilidades de ação (agenciamentos), o que obriga o sujeito a produzir um sentido próprio de sua experiência, a partir de sua capacidade de articular diferentes processos socializadores. Dito de outro modo, a socialização de gênero resulta de uma série cada vez mais contingente e diversificada de experiências produzidas pelos próprios indivíduos no decurso de suas vidas.

Outro processo paralelo ao vivenciado pelas crianças na UMEI diz respeito à socialização de gênero vivida por meninos e meninas no âmbito familiar. Importante destacar que esse processo ora se alinha com a socialização de gênero imposta pela UMEI, ora se distancia dele. Nas entrevistas, as crianças apresentaram indícios da presença dessa socialização no processo de construção de suas experiências sociais. Quando perguntadas sobre as diferenças que envolvem as ações de meninos e meninas, as crianças demonstraram que tais diferenças são "aprendidas" por meio das intervenções de familiares: 


\begin{abstract}
"Meninos não podem catar florzinha! Sempre que a gente está vindo para a Escola e o Kalebe quer parar pra pegar flor pra professora dele, o meu pai fala que isso não é coisa de menino. Eu acho que ele pode até catar flor para dar para a professora dele, mas pra ele mesmo, não. Flor é coisa de menina”! (Flaviane, 15 de setembro de 2015).
\end{abstract}

"A minha mãe não deixa eu jogar bola com meus irmãos. Ela fala que mocinha não pode fazer isso. Mas a Wânia deixa a gente jogar. Ela até joga também, tem vezes. Aí eu brinco de bola aqui na UMEI” (Andréia, 15 de setembro de 2015).

Willian: "Homem não pode passar maquiagem. Minha vó disse que se passar, vira gay".

Pesquisador: Como assim? "Como é ser gay"?

Willian: "Gay é homem que vira mulher. Que faz coisas de mulher. É homem que quer ser mulher” (Willian, 23 de setembro de 2015).

Como percebemos nas falas acima, as experiências de gênero vivenciadas no ambiente familiar são construídas pelas crianças na interação com seus entes (seja por meio de relações mais verticais: entre as crianças e os adultos - seus pais, mães, avôs, avós, tios, tias -; seja nas relações mais horizontais: entre as crianças e seus irmãos, irmãs, primos e primas) que insistem em fiscalizar, orientar e prescrever modos de subjetivação masculinos e femininos. Tais prescrições objetivam não somente a construção da identidade de gênero das crianças, mas contribuem para que meninos e meninas incorporem papéis sociais de gênero. Desse modo, os relatos das crianças no âmbito das entrevistas são reveladores de diálogos entre elas e os adultos nos quais os últimos associam a imagem dos meninos/homens à virilidade e a dureza/frieza, com expressões do tipo: "meninos não podem catar florzinhas!"; “Não podem passar maquiagem”; "Homem não chora"; dentre outras afirmações. Em contrapartida, as meninas afirmam que no interior de suas famílias, é comum que elas iniciem, desde cedo, a aprendizagem dos serviços domésticos - tal como propõe Gláucia: "Minha mãe fica em casa só fazendo comida, arrumando a casa e lavando vasilha. Eu já lavei vasilha com ela. Ela me ensinou". Ou seja, diferentes poderes e diferentes expectativas se conjugam e se diferem na socialização das meninas e dos meninos, tal como investigou Belotti (1975 [1973]).

Nas entrevistas com as crianças, percebe-se também que existe, por parte não só dos pais e das mães, mas também de membros da família extensa (como no caso da avó de William) uma marcante preocupação com a construção da identidade de gênero por parte de meninos e meninas, alinhando-a com padrões hegemônicos de masculinidade e feminilidade (que se aproximam da heterossexualidade). Mas, se por um lado, as crianças revelam formas de controle e vigilância dos adultos nas relações familiares, por outro, na UMEI, é possível que meninos e meninas vivenciem experiências socialmente indicadas ao sexo oposto (como no caso de Andréia, que afirma que é impedida por sua mãe de brincar com seus irmãos de futebol, mas que tem a possibilidade de fazê-lo na instituição, seguindo os passos de sua professora, que, conforme explica a menina, às vezes também joga). As falas das crianças permitem inferir que o controle realizado pelos familiares expressam diversas expectativas adultas acerca de 
comportamentos socialmente adequados para meninos e meninas. Kishimoto e Ono (2008) afirmam que os padrões de gênero não são originalmente criações das crianças, mas sim construídos pelos adultos que as cercam.

Desse modo, sendo o ambiente familiar o primeiro contexto de relações sociais em que a criança vive, este espaço é responsável por produzir os primeiros modelos de gênero aos quais meninos e meninas têm acesso (KISHIMOTO e ONO, 2008), sejam estes estereotipados ou não. Percebe-se que os adultos, ao demarcarem comportamentos destinados às crianças, acabam reforçando um suposto ordenamento dos corpos que incide também sobre as relações sociais, instaurando condutas demarcadoras de lugares sociais de crianças e adultos, meninas e meninos, homens e mulheres. Além disso, as expectativas dos pais e demais entes acerca dos comportamentos mais adequados para seus filhos e filhas contribuem para as construções das identidades de gêneros das crianças, pois no âmbito familiar, meninos e meninas se encontram circunscritos(as) por um espaço limitado de comportamentos e de ordenamentos específicos a cada um dos gêneros.

Assim como nas entrevistas, no âmbito das conversas relativas à produção dos desenhos, as crianças acenaram para a pertinência dos processos de socialização de gênero oriundos dos contextos familiares de origem na produção de suas experiências sociais:

Figura 2: desenho de Flaviane

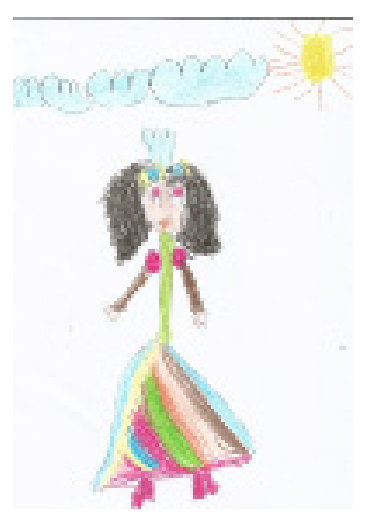

Fonte: arquivos da pesquisa

Pesquisador: - "O que você desenhou"?

Flaviane - "Desenhei: eu, fazendo comida. Quando eu crescer, quero ser cozinheira".

Pesquisador: - "É mesmo? Parabéns! E vem cá: você acha que existe algum trabalho de mulher que homem não pode fazer"?

Flaviane: - "Tem".

Pesquisador: - "Qual”? 
Flaviane: - "Homem não arruma casa".

Pesquisador: - "Não"?

Flaviane: - "Não. Meu pai não ajuda minha mãe. Nem o Kaleb ajuda a mim e às minhas irmãs".

Pesquisador: - "Por que será, hein"?

Flaviane - "Ah, eles não sabem fazer nada”. (Ana Flavia desenha o que vai querer ser quando crescer - 01 de setembro de 2015)

Figura 3: desenho de Vitório

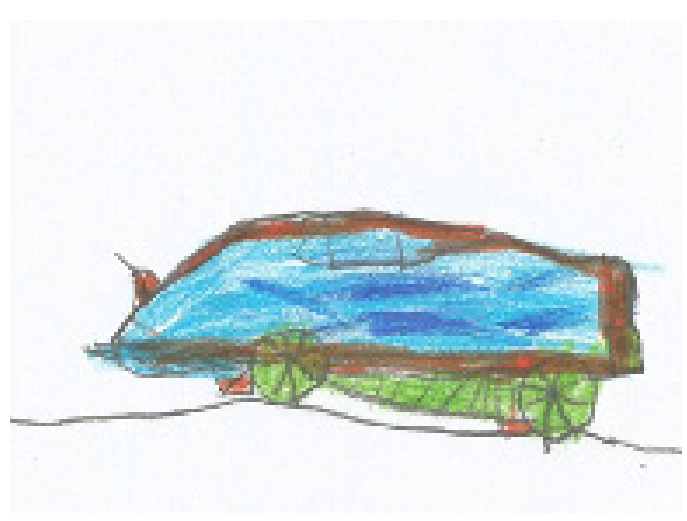

Fonte: arquivos da pesquisa

Pesquisador: - "E tem algum brinquedo que você não gosta"?

Vitório: - "Ah eu não gosto de boneca... essas coisas".

Pesquisador: - "Por quê"?

Vitório: - "Porque minha mãe fala que isso não é coisa de menino. Menino brinca é de carrinho". (Vitório desenha "o brinquedo que eu mais gosto - 27 de agosto de 2015)

Diferentes arranjos de gênero estão presentes no âmbito das organizações familiares das crianças. Nesse sentido, tais modelos não apontam todos na mesma direção, sendo por vezes, imprecisos e conflitantes. Se as relações vivenciadas no ambiente familiar são geradoras de representações de gênero, os arranjos, acordos e negociações realizados pelos entes no interior das organizações familiares produzem outros sentidos para o ser homem e mulher; menino e menina, haja vista que não abarcam apenas formas consideradas hegemônicas de vivenciar a masculinidade e a feminilidade, como podemos identificar nas falas de algumas crianças que, ao relatar sobre as práticas de preparo dos alimentos em suas respectivas famílias, afirmam que homens (mesmo circunstancialmente) dividem tarefas domésticas com as mulheres: 
"Lá na minha casa a minha mãe faz comida e minha vó também. Tem dia que até meu tio faz comida. Ele sabe cozinhar. O tio Rodrigo faz até bolo" (Mário, 23 de setembro de 2015).

"Minha mãe é quem faz a comida pra gente almoçar e jantar. Às vezes, quando ela vai para a célula [reunião da igreja] o meu pai faz. Quando eu e minha mãe saímos, meu pai é quem arruma a casa toda" (Welington, 23 de setembro de 2015).

"Quando a minha vó sai e demora, é meu avô quem faz a comida e dá para a gente [ele e sua irmã]” (Carlos, 21 de setembro de 2015).

Tais questões evidenciam os modos casuais de participação dos pais/padrastos/homens nos afazeres domésticos, como cozinhar. Isso também foi percebido nas conversas que decorriam das produções gráficas de algumas crianças:

Figura 4: Desenho de Andreia Juliane

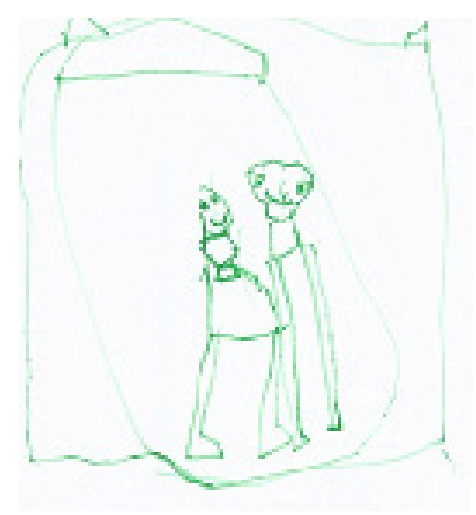

Fonte: arquivos da pesquisa

Pesquisador: - "Quem você desenhou Andreia Juliane”?

Andreia Juliane: - "Eu fiz meus dois irmãos: o Gabriel e o Rafael”.

Pesquisador: - "São seus irmãos"?

Andreia Juliane: - "Sim”!

Pesquisador: - "E o que eles fazem? Eles trabalham, estudam”?

Andreia Juliane: - "Eles jogam videogame; mexem no computador; ajudam minha mãe. Eles lavam vasilha, arrumam a casa, porque minha mãe fala que eles têm que ajudar. Até meu pai ajuda quando ele não está trabalhando"! (Andreia Juliane desenha "eu e meus irmãos" - 13 de agosto de 2015).

As falas e os desenhos das crianças apresentados acima demonstram que, embora os pais/homens ajudem as mães/mulheres nas tarefas de casa, esse auxílio é realizado de modo esporádico. Embora algumas crianças afirmem que em suas famílias pais, tios e avôs desempenhem algumas funções que, no âmbito familiar, são conside- 
radas atributos femininos, os homens o fazem de modo espaçado ou pouco recorrente, como no caso relatado por Mário, que afirma que "tem dia" que até seu tio faz comida; ou no caso de Welington, que afirma que, "às vezes" quando sua mãe vai para a igreja, seu pai faz comida e arruma a casa; ou ainda no caso de Carlos que relata que "quando" sua avó sai e demora, seu avô é quem cozinha.

Os homens geralmente se envolvem em tarefas domésticas de maneira bastante seletiva. Para Bruschini (2007), quando os homens se propõem a ajudar as esposas nas tarefas de casa, ajudam naquilo que se sentem aptos ou que preferem fazer. Segundo a autora, os homens, ao ajudarem suas esposas, dividem com elas os encargos domésticos,

Apenas em atividades específicas - como as de manutenção ou conserto - de maneira eventual e a título de ajuda ou cooperação. [...] Os homens se envolvem, preferencialmente, em atividades interativas, como cuidar dos filhos, nas que envolvem interseção entre os espaços público e privado, como fazer as compras da casa ou levar os filhos ao médico, nas atividades intelectuais - como ajudar os filhos nos deveres escolares - em oposição às manuais ou rotineiras como lavar roupa ou limpar a casa - ou ainda em tarefas domésticas valorizadas - como realizar uma culinária mais sofisticada (BRUSCHINI, 2007, p. 543).

Considerando que a família é a primeira instituição que se ocupa da socialização de meninos e meninas, ela também é responsável pela gradual inserção das crianças nas práticas culturais, dentre as quais se destaca a religiosidade. Nas entrevistas, algumas crianças afirmam que as instituições religiosas das quais participam também laboram na produção de sujeitos masculinos e femininos, disseminando suas expectativas sobre os modos de ser menino e de ser menina:

"A tia Martinha da minha igreja [escola dominical] disse que menino não tem que brincar de boneca. Se brincar vira mulherzinha" (Cristiano, 21 de setembro de 2015).

"Lá na minha igreja, eu aprendi que não pode dançar essas músicas do mundo... tipo... essas que as meninas brincam de ensaiar. Por isso que eu não brinco com elas de 'show das poderosas"'! (Flaviana, 22 de outubro de 2015).

Assim, coadunando com a socialização de gênero vivida na família, as crianças também têm contato com processos de socialização de gênero provenientes das instituições religiosas das quais participam, o que é perfeitamente identificável no episódio a seguir:

Hoje, as crianças, juntamente com a professora, ensaiaram a apresentação para a festa junina. Percebi que algumas crianças não participaram dos ensaios. Ao verificar com a professora percebo que as famílias (por serem de religiões protestantes) não autorizaram a participação dessas crianças nas festividades. Sento-me próximo a essas crianças e percebo que as meninas se comportam de modo distinto dos meninos. Enquanto eles ficam brincando entre si, as duas meninas se alternam em situações de transgressão e de obediência às normatizações religiosas de suas famílias. Andréia, mesmo 
sabendo que sua mãe havia lhe proibido de participar da festa junina, se mistura entre as crianças e ensaia a coreografia. A professora percebe que essa menina está dançando, mas, não a reprime. Em contrapartida, Flaviana, sentada a meu lado, fica tapando os ouvidos e falando:

Flaviana: - "Não gosto dessa música feia"!

Pesquisador: - "Feia? Por quê? Por que você acha essa música feia”?

Flaviana: - "Porque sim! Música bonita é música que fala de Deus"!

Pesquisador: - "E essa então não é boa”?

Flaviana: - "Não"!

Pesquisador: - "É por isso que você não vai dançar"?

Flaviana: - "É! Deus não gosta dessas músicas feias. Se eu dançar músicas assim Deus fica chateado comigo".

Pesquisador: - "Ah tá! Então é melhor ficar aqui né”?

Flaviana: - "É"! - a menina fica insistentemente tapando as orelhas demonstrando sua indignação com as músicas do ensaio (Notas do caderno de campo, 11 de junho de 2015).

Importante destacar as diferentes agências que as meninas (Andreia Juliane e Flaviane) assumem frente à impossibilidade de participarem dos ensaios das coreografias para as festividades juninas. Andreia Juliane, mesmo sabendo que não participaria da festa junina, engaja-se nos ensaios participando da dança - é preciso relembrar que Andreia Juliane é a mesma menina que afirma ser proibida pela mãe de jogar bola com os irmãos e que, alega poder realizar essa experiência na UMEI. Desse modo, reafirma-se que essa menina encontra na instituição de Educação Infantil um terreno fértil para suas transgressões.

Já Flaviane, insistentemente, nega-se a participar dos ensaios enfatizando que aquelas músicas seculares eram feias, pois não falavam de Deus. E mais: que Deus ficaria triste com a menina se ela participasse daquela dança. Desse ponto de vista, é preciso considerar que a religião se conforma como um sistema cultural que incide sobre os modos de ser e estar no mundo dos indivíduos. Para Geertz (1989 [1973], p. 67), a religião se configura como:

(1) um sistema de símbolos que atua para (2) estabelecer poderosas, penetrantes e duradouras disposições e motivações nos homens através da (3) formulação de conceitos de uma ordem de existência geral e (4) vestindo essas concepções com tal aura de factualidade que (5) as disposições e motivações parecem singularmente realistas.

Para esse autor, a religião, enquanto sistema cultural alinha as ações humanas a uma ordem mística ao passo que, dialeticamente, projeta imagens dessa ordem mística no plano existencial da experiência humana. Desse ponto de vista, Geertz considera que a religião produz uma forma de construção de significado para experiência humana atribuindo-lhe sentidos (que podem ser de ordem moral, cognitiva e até mesmo afetiva). 
De um modo geral, pesquisas sobre religião na infância, embora escassas, destacam a relevância do ponto de vista da criança, enfatizando que sua percepção e seu posicionamento sobre as práticas religiosas se difere da percepção e do posicionamento dos adultos. Pires (2007), por exemplo, afirma que existem diferenças entre os sentidos da prática religiosa para as crianças (que comumente a associam ao ato de ir à igreja/templo) e dos adultos (que a relacionam ao abstrato - à figura de Deus). Essa autora, baseada em estudos antropológicos, afirma que, por volta dos nove anos de idade, as crianças passam a alinhar o sentido da experiência religiosa àqueles sentidos produzidos pelos adultos.

Contudo, as diferentes agências dessas duas meninas, demonstram a fragilidade desses argumentos, pois, o fato de Flaviane se recusar a participar do ensaio, mesmo presenciando a transgressão dessa norma por parte da Andreia Juliane, não pode ser visto como uma experiência religiosa menor do que aquelas vivenciadas pelos adultos, mas sim, diferente (COHN, 2005).

Percebe-se, desse modo que, as instituições religiosas atuam também no processo de socialização de gênero das crianças. A experiência de cada uma dessas meninas varia de acordo com o conjunto de significados sociais que elas possuem sobre a prática religiosa. Contudo, apesar das discrepâncias entre as posturas das meninas frentes à interdição de ensaiar uma dança tradicionalmente associada ao catolicismo, percebe-se que de um modo ou de outro, a experiência religiosa é apreendida pelas crianças de modo situado, configurando-se como uma aprendizagem na prática social (BERGO e GOMES, 2009). No caso das meninas, não cabe refletir se Deus fica chateado ou não com as crianças que dançam músicas seculares, mas sim como essa "crença" orienta a ação das crianças a ponto de fazer com que Flaviane não participe da brincadeira, mesmo percebendo que a instituição de Educação Infantil permita tais transgressões, como as realizadas por Andreia Juliane.

Compreende-se que o processo de socialização de gênero no interior das práticas familiares, progressivamente, se adensa ao ser realizado também por outras instâncias sociais. A inserção das crianças nas instituições religiosas possibilita a emergência de processos subsequentes e complementares à socialização de gênero vivenciada em âmbito familiar. Assim, a religiosidade é vista como uma dimensão da vida cotidiana que também se articula ao gênero de diferentes maneiras para estruturar as experiências de meninos e meninas não só na vida familiar, mas também na vida escolar.

\section{Considerações finais}

Confessando bem todo mundo faz pecado logo assim que a missa termina. Todo mundo tem um primeiro namorado; Só a bailarina que não tem

(Chico Buarque, 1983).

Retomando a beleza dos versos de Chico Buarque, assim como no preâmbulo deste artigo, a guisa de encerramento, tecemos algumas considerações finais enaltecidos pela lucidez das palavras desse artista. Neste estudo, buscou-se evidenciar 
como a socialização de gênero vivenciada pelas crianças na Educação Infantil conjuga diferentes e complexos processos socializadores, nos quais meninos e meninas interagem com os adultos, com seus pares, com a cultura e com a sociedade.

Cumpre explicitar que, no cotidiano institucional, ao se observar os indivíduos (adultos e crianças) agindo sobre o mundo e nas relações sociais em que cotidianamente se envolvem, evidencia-se que diferentes masculinidades e feminilidades transitam pela instituição de Educação Infantil e orientam distintos processos socializadores, contrariando visões anteriormente presentes em nosso imaginário coletivo que compreendiam apenas a masculinidade e a feminilidade hegemônicas (CONNELL, 1995) como legítimas. Pensar as representações de gênero como conceitos plurais, põe em xeque a hegemonia destas representações, comumente vistas como universais e essencialistas e que são impostas a homens e mulheres, meninos e meninas (CONNELL e PEARSE, 2015). Nesse sentido, é preciso pensar que no convívio (e no confronto) entre essa pluralidade de masculinidades e de feminilidades, variadas representações de gênero ora se articulam, ora concorrem, ora se contradizem nos processos de socialização vivenciados pelas crianças nas diversas instituições sociais das quais participam, como no caso da instituição de Educação Infantil pesquisada.

Ampliando o foco de análise, percebe-se que no âmbito da Educação Infantil, diversas instâncias socializadoras ora se mesclam, ora concorrem, o que pode ocasionar discursos ambíguos, tensões e atravessamentos. Nas breves linhas deste artigo, optou-se por discutir a socialização de gênero vivenciada na Educação Infantil, na família e nas instituições religiosas das quais as crianças participam. Por certo, muitos outros processos de socialização de gênero se alinham (ou se contrapõem) àqueles vivenciados na instituição de Educação Infantil - por exemplo, os processos de socialização de gênero disseminados pelos veículos midiáticos ${ }^{5}$.

A juntura de distintos processos de fabricação de sujeitos gendrados provenientes de diferentes instituições conduz as crianças a articular diversas formas de ação nos próprios processos de socialização, como no caso de Andréia, que sendo proibida de jogar bola com os irmãos mais velhos (por proibição de sua mãe) o faz na escola (em função da participação da professora em brincadeiras como essa); ou no caso relatado por Cristiano, no qual ele afirma que Mirela, ao ser proibida pela professora de brincar de lutinha, se vê obrigada a utilizar jogos de encaixe. Como dito anteriormente, o entrecruzar desses processos, muitas vezes proporcionam avanços e retrocessos, descontinuidades e rupturas, ou seja, sucessivas dessocializações e ressocializações (MOLLO -BOUVIER, 2005), não ocorrendo de modo linear e unilateral.

Em suma, a discussão ora apresentada endossa a necessidade de ampliação dos estudos e pesquisas que aprofundem a compreensão sobre a juntura de distintos processos socializadores provenientes de diferentes instituições sociais, mas que têm o mesmo objetivo: produzir sujeitos de gênero. Igualmente, reitera-se a necessidade de que estes estudos levem em consideração o ponto de vista das crianças. 


\section{Referências}

BEAUVOIR, Simone. O segundo sexo. Rio de Janeiro: Nova Fronteira, 1980 [1949].

BELOTTI, Elena Gianini. Educar para a submissão - o descondicionamento da mulher. Petrópolis: Vozes, 1975 [1973].

BERGO, Renata Silva; GOMES, Ana Maria Rabelo. "Eu sou muzenza": a aprendizagem no terreiro de umbanda. Associação Nacional de Pesquisa e Pós-Graduaçâo em Ciências Sociais. Trabalho apresentado na ANPOCS. 2009

BRUSCHINI, Maria Cristina Aranha. Trabalho e gênero no Brasil nos últimos dez anos. Cadernos de pesquisa, v. 37, n. 132, 2007. p. 537-572.

BUARQUE, Chico. Ciranda da Bailarina. In: LOBO, Edu e BUARQUE, Chico. O Grande Circo Místico. Interpretação: Coro Infantil, CD. 1, faixa 8.1983.

COHN, Clarice. Antropologia da Criança. São Paulo: Jorge Zahar, 2005.

CONNELL, Raweyn; PEARSE, Rebecca. Gênero: uma perspectiva global. Tradução e revisão técnica de Marília Moschkovich. São Paulo: nVersos, 2015.

DURKHEIM, Émile. Educação e Sociologia. Tradução de Stephania Matousek. - Petrópolis, RJ: Vozes (coleção textos fundantes de Educação), 2011 [1922].

FINCO, Daniela. Encontro com as diferenças na Educação Infantil: meninos e meninas nas fronteiras de gênero. Leitura: Teoria \& Prática, Campinas, v.31, n.61, nov. 2013. p.169-184.

GEERTZ, Clifford. A interpretação das culturas - 1. ed., 13a reimpressão. - Rio de Janeiro: LTC, 1989 [1973].

GRAUE, Elizabeth; WALSH, Daniel J. Investigação etnográfica com crianças: teoria, métodos e técnicas. Lisboa: Fundação Calouste Gulbenkian, 2003.

KISHIMOTO, Tizuko Morchida; ONO, Andréia Tiemi. Brinquedo, gênero e educação na brinquedoteca. Pro-Prosições. vol. 19, n.3, 2008. p. 209-223.

LOURO, Guacira Lopes. Gênero, sexualidade e educação: uma perspectiva pós-estruturalista. 8a ed. - Petrópolis: Vozes, 1997.

MOLLO-BOUVIER, Suzanne. Transformação dos modos de socialização das crianças: uma abordagem sociológica. Educação \& Sociedade. Campinas, vol. 26, n. 91, 2005, p. 391-403.

PIRES, Flávia Ferreira. Ser adulta e pesquisar crianças: explorando possibilidades metodológicas na pesquisa antropológica. Revista de Antropologia (USP), 2007.

PROUT, Alan; JAMES, Allison. A new paradigm for the Sociology of childhood? Provenance, Promise and Problems. In: JAMES, Allison; PROUT, Alan (Ed.). Constructing and Reconstructing Childhood: Contemporany Issues in the Sociological Study of Childhood. London 1997 (second edition). The Falmer Press. p. 7-34.

SARMENTO, Manuel Jacinto. Conhecer a infância: os desenhos das crianças como produções simbólicas. In: MARTINS FILHO, Altino José; PRADO, Patricia Dias. Das pesquisas com crianças à complexidade da infância. Campinas, São Paulo: Autores Associados, 2011. p. 27-60.

SARMENTO, Manuel Jacinto. Sociologia da Infância: correntes e confluências. In: SARMENTO, Manuel Jacinto; GOUVEA, Maria Cristina Soares (orgs). Estudos da Infância: educação e práticas sociais - Petrópolis: Vozes, 2008. p. 17-39.

SILVA, Isabel de Oliveira e; LUZ, Iza Rodrigues da. Meninos na Educação Infantil: o olhar das educadoras sobre a diversidade de gênero. Cadernos Pagu. 2010, n.34, p. 17-39.

WEST, Candace; ZIMMERMAN, Don H. Zimmerman. Doing Gender. Gender and Society, Vol. 1, No. 2, 1987.p. 125-151. 
${ }^{1}$ Embora as crianças convivessem diariamente com dois profissionais de Educação Infantil - a professora referência (mulher) e o professor de apoio (homem) - para fins desse artigo, serão apresentados dados relativos apenas à docente.

${ }^{2}$ Pires (2007, p. 242) afirma que "os desenhos úteis para a pesquisa antropológica são, sem dúvida, aqueles nos quais as crianças se esmeraram nos comentários”. Com isso, deixamos claro que não analisamos os desenhos em si, mas o que as crianças diziam no momento da produção dos mesmos.

${ }^{3}$ É preciso considerar que, na atualidade, presenciamos a emergência de diferentes sujeitos na cena social e, nesse sentido há pessoas que não se encaixam nesta polaridade, como no caso dos andrógenos, os transex, intersex, enfim, homens e mulheres em processo de desconstrução do binarismo de gênero.

${ }^{4}$ Connell e Pearse buscam compreender os modos pelos quais os processos corporais e as estruturas sociais se conectam pelo tempo. Segundo as autoras, as relações de gênero "somam-se ao processo histórico no qual a sociedade é corporificada e os corpos são arrastados para a história”, processo ao qual Connell e Pearse (2015, p. 112) nomeiam como corporificação social, isto é, uma espécie de "prática corporal reflexiva", no caso das condutas sociais em que os corpos são simultaneamente agentes e objetos.

${ }^{5}$ Ainda que no âmbito da pesquisa, a socialização de gênero proveniente de produtos com amplo apelo midiático tenha sido discutida em profundidade, optamos por não apresentá-la aqui, em função dos limites desse artigo.

* Professor doutor da Universidade Federal dos Vales do Jequitinhonha e Mucuri, Diamantina, Minas Gerais, Brasil.

\section{Correspondência}

Sandro Vinicius Sales Santos - Universidade Federal dos Vales do Jequitinhonha e Mucuri - Campus JK. Rodovia MGT 367 - Km 583, no 5000, Alto da Jacuba. CEP: 39100-000. Diamantina, Minas Gerais, Brasil.

E-mail: sandrovssantos@gmail.com

Recebido em 27 de julho de 2017

Aprovado em 10 de outubro de 2017 